\title{
Integration of B2B E-commerce and ERP in Manufacturing Enterprise and
}

\section{its Application}

\author{
Cai Ting ${ }^{1}$; Liu Lei ${ }^{2}$ \\ 1 Jiangxi Industry Polytechnic College, Electronic and Information Engineering Branch; Jiangxi \\ Nanchang; 330095 \\ 2 Jiangxi Industry Polytechnic College, Electronic and Information Engineering Branch; Jiangxi \\ Nanchang; 330095
}

Keywords: Manufacturing Enterprises; B2B E-commerce; ERP; Integration and Application

\begin{abstract}
The advent of the information age and the emergence of enterprise resource planning, all have brought the greatest advantage for enterprise integration of resources; a B2B e-commerce business model has formed and become a main trading method of the business development; in the age of electronic commerce, one-to-one market-based approaches, personalized orders and demand, as well as online customer service and other new business operations and service model, are not what traditional ERP system had expected; especially the emergence of flexible production, small batch production, etc., enable a wider range and more content of inter-corporate transactions; hence, the traditional ERP systems have to change from the corresponding structure and business functions, and many other aspects. E-commerce precisely provides an excellent support platform in response to this change. In addition, with funding from traditional enterprises, especially from large enterprises invested into the field of B2B, integration and applications of B2B e-commerce and ERP of manufacturing enterprises will become an inevitable trend.
\end{abstract}

\section{Introduction}

With the advent of the Internet age, the fast development speed of Internet makes e-commerce an essential business development mode of modern society, in which B2B is also transaction method of the corporate. ERP is a representative of management technique suitable for manufacturingenterprise. It uses the latest achievements of information science, conducting an overall planning, coordination arrangements and strict control on the resources of internal enterprise and all sectors of supply chain on according to market demand, in order to guarantee adequate and reasonable applications of manpower, financial, material, information and other resources, and improve productivity, reduce costs, meet customer demand, and enhance the competitiveness of enterprises.

The current B2B e-commerce is completed via the Internet, but if there is no ERP system as the internal support for enterprise, it is difficult to imagine how e-commerce will receive orders via the Internet. Still, the order should be printed out, transferred into the artificial production management system for implementation, and then, after warehousing, it will be input to business processes of Internet. Thus, ERP is a support for e-commerce, and integration between ERP and e-commerce is a necessity.

Taking speed and accuracy as a precondition, e-commerce has proposed important requirements to business-to-market reflected speed and collaboration ability between enterprise and external 
resources; if there is inadequate efficient integration of resources within and between the enterprises, it is hard to quick reflec to the market. The integration between e-commerce and ERP enables enterprise management mode to be a full connectivity from the client to the supplier, fully integrating internal processes and external transactions. However, there are many problems in E-commerce and building of ERP.

(1) The poor implementation of ERP system lies in the lack of clear standard to jud ge the success of ERP project implementation in the industry. It could not determine whether a successful ERP implementation is successful or not merely from the economic profit, cost savings and schedule meeting.

(2) E-commerce relies on business development, while ERP is commercial software directly bought from the market. The two systems are independent without unified planning and design, resulting in data resources under the two systems do not share with each other, such as procurement data, sales data and financial data can not be called. Hence resulting in a lot of duplication of effort, as well as data consistency and integrity.

(3) The enterprise fails to have in-depth study on the relationship between e-commerce and ERP. The one-sided understanding of e-commerce as building a website, doing some corporate image advertising, product introduction and service guide, etc., lead to the misinterpretation of the ERP as a status symbol: the enterprise just either spends large sums of money to buy, but does not know how to use it; or is reluctant to implement ERP .

(4) Software resources, hardware resources and data resources are not fully shared, resulting in high construction costs and waste of storage space.

(5) ERP is the software directly from commodity market, while e-commerce is a self-develop one. It can not achieve the integration of the two sessions.

\section{Integration Approach of B2B E-commerce and ERP in Manufacturing Enterprises}

Design the integration. Both sales model must conduct reductions on the same product inventory, sales must be reflected in the marketing department, and get summarized in marketing department so as to provide data for the market needs analysis; two purchasing patterns must have incremental inventory for the same inputs, sales must be reflected to the planning and production department, and get summarized there so as to provide data for the market needs analysis; two modes can share inputs number or product number database, vendor database, customer database and other related databases, hence enable the existing and future database sharing; financial income and expenses including accounts payable in the two modes, must be reflected and summarized in the Finance Department for analysis of financial indicators.

Integration of functions. In carrying out the integration of both, e-commerce should consider sites management module, online sales module, online procurement module and online money payment module; ERP should give priority to the procurement, production planning, marketing, sales, inventory, finance modules that are closely related to logistics and cash flow. Integrate the modules of both aspects into a new application system, which is called integrated system. Integrated system should reserve interface for future modules expansion, laying the foundation for future seamless connection between systems.

Integration of systems. System could be developed by Java language or .NET platform; the application is based on Internet B / S structure database application; the client uses a browser. Since the wide popularization and low prices of the Internet, businesses can use the Internet system to set 
up inventory and sales management system facing the national and even global scope. System host via Digital Data Network, a relay or a broadband connects to the Internet; the offices or clients in other placed could get access to the Internet through leased line connections and the host application. The corporate headquarters via LAN could get direct access to the host. At the same time, the rise of Extensible Markup Language (XML) has provided an open standard to achieve safe and efficient network services and e-commerce, especially the inexpensive and practical character making it the future direction of the software industry.

Integration of talents and ideas. E-commerce and ERP integration affects the whole, involving all aspects of business, which is a deep change inside corporate. It requires the highest policy level to promote and guide, and ask business managers to have computer knowledge, IT technology staff to have management knowledge and business theory. Only in this way can enterprises have a clear understanding on the ERP needs of e-commerce, and the know-how of technical achievement. If there is the lack of compound talents, companies will be unable to effectively implement the integration of e-commerce and ERP.

Integration of architectures. Implementation of E-commerce and ERP integration is achieved through the supply chain management and customer relationship management; the integration of e-commerce and ERP has achieved the complete connectivity from the customer to the vendor, a fully integrated internal processes and external transactions achieved customer interactive marketing, consumer behavior research and sales forecasting through customer relationship management, forming one-to-one effective target market, and identifying customer value.

\section{Key of B2B e-commerce and ERP Integration in manufacturing enterprises}

Compatibility based on supply chain. In general, there are three "flows" in businesses: logistics, cash flow and information flow. Among them, the information flow is not isolated, and is closely related to logistics and cash flow, reflecting the situations of before, during and after material flow. Correspondingly, there are materials supply chain, financial supply chain and information supply chain. E-commerce mainly involves the procurement and sales business, so the online procurement department and online sales department become a part of the business logistics and cash flow. Although ERP first uses supply chain management thinking, supply chain doesn't depend on ERP as a objective reality of corporate; any enterprise application systems can use ideas and methods of supply chain management. Thus, by restructuring of organizational structure and business process, e-commerce can be included in the supply and demand chain

Auxiliary based on business processes. E-commerce can provide additional support to all levels. For example, it can provide online advertising, online consumer surveys, customer feedback and other supports for marketing. ERP system acts on the entire enterprise business processes, and its application has three levels: the data query and comprehensive analysis of decision-making level, management and control of middle management level, and the business achievement of operational level.

Auxiliary based on the application. According to internal and external conditions of current business, during the introduction of e-commerce, companies will not completely abandon the traditional procurement and sales model, but use two models, two systems for complement. Enterprises using e-commerce can reduce circulation, transaction costs, speed up capital turnover rate, improve marketing capabilities, expand domestic and foreign markets, facilitate customer information records, improve customer service system, strengthen customer relationship 
management, and promote production-oriented management into a market-oriented management .

The relevance based on customer relationship management. Customer Relationship Management is a development direction of ERP system. CRM gives customers the ability to communicate with the enterprise, while this exchange is carried out through e-commerce model. Running of e-commerce systems provides intermediary for the exchange between customers and enterprises, and also provides the most direct data to ERP, which is more convenient, and cost-effective.

Difference of focus. E-commerce focuses on external trade, which has closely linked the enterprise with suppliers and customers, namely internal and external information; ERP system focuses on internal processes; it is the management tool of various departments within the enterprise. With the rapid development of computer network technology and the advent of the electronic management thinking, business management software also constantly adjusting to changes in the Electronic Age, with specific performance is as follows:

First, in the age of electronic commerce, internal and external operation mode will be greatly changed.

Second, with a wide range of e-commerce applications on the Internet, external interfaces of enterprise have been greatly expanded.

Thirdly, with the increasingly fierce market competition, different company's products and services themselves are difficult to be separated from absolute pros and cons, and the supply chain, which unified the customers, suppliers and partners has become integral competition core among enterprises.

Fourth, with the development of e-commerce technology, various foreign business activities of enterprises have also extended to the Internet; enterprise management software should support the access to information on the Internet and online trading. However, there are some drawbacks in the traditional ERP.

Thus, to meet the new demands of e-commerce era, ERP systems need to consider several factors:

(1) System integration, including the full integration of internal business (production, supply, marketing, finance, personnel, etc.) as well as the external resources of supply chain (logistics network planning, transportation management, customer and marketing management, etc.) integration capabilities ;

(2) Advanced technology should have the ability to integrate with an open e-commerce platform, which is critical to the realization of true sense supply chain management;

(3) Advanced idea and forward-looking, such as the personalized application, and comprehensive collaborative commerce;

(4) Extensibility of system, so that enterprises can timely changes with market conditions and adjust the appropriate business processes in the future, without the repeated IT investment.

Therefore, e-commerce must be integrated into ERP, which means enterprise based on development and business processes, combine, revoke or increase the number of business sectors, including horizontal integration and vertical integration. E-commerce and ERP integration requires the cooperation of business process reconstruction, but also requires a reasonable division and organic integration of all application software modules.

Achieving integration of the two is a huge and complicated project, which has involved business restructuring, data sharing, of personnel adjustment, hardware and software other reconstruction, etc., and also requires a certain human, financial, energy investment as well as solidarity. In the specific 
implementation, purchase and sales of same product in the two modes must have increase and decrease records in the inventory, and the data should be aggregated to provide data for market supply and demand analysis; two models can share with all relevant databases, reducing data redundancy, and keeping consistency, completeness and accuracy of the data.

In order to ensure better integration of ERP and B2B e-commerce, reconstruction of hardware and software is also an important factor. In the integration process, due to the demanding requirement of real-time systems, data traffic increases, hence the reaction rate and response capacity to hardware and software have accordingly increased, which requires the enterprises to update some facilities according to the actual situation. For the companies with relatively mature ERP implementation, they should develop the corresponding e-commerce module based on ERP modules, and extend ERP application; in the planning and development process the interface should be set aside, so as to lay the foundation for future upgrades.

\section{Conclusions}

ERP is a product of modern management thinking, which has reflected many advanced management in the ERP software system, such as agile manufacturing, lean production, concurrent engineering, supply chain management, and total quality management. It has become a new modern management tool for manufacturing enterprises. E-commerce application has expanded the extension of ERP, making it come to the front from the back and from the inside to the outside. ERP effectively plans and controls the enterprise resources, optimizes the use of resources, and implements network management on internal flow, logistics, capital flow, and information flow, providing the material basis for enterprises to carry out e-commerce. If the e-commerce and ERP are integrated with each other, it is difficult to ensure the organic unity of enterprise logistics, capital flow and information flow, and also, it is hard to ensure consistency, completeness and accuracy of the data.

\section{References}

[1] Chen Aihong. Discussion on ERP System under the Modern E-commerce [J]. Managers, 2009, (18).

[2] Li Yan, Yang Yong. Research of E-commerce and ERP Integration [J]. Business Economy, 2010, (01).

[3] Zhang Yi. Discussion on the Integration of ERP and E-commerce Systems [J]. Journal of Management Studies, 2011, (04).

[4] Cheng Miao. On the Integration of ERP and E-commerce [J]. Friends of Science, 2010, (22).

[5] Cao Jun, He Da. New Development and Opportunities Brought by E-commerce into the Traditional ERP. [J]. Management \& Technology (first half of the month), 2010, (12)

[6] Zhou Jin. On the E-commerce and ERP Integration [J]. Huainan Vocational and Technical College, 2010, (02).

[7] Fang Xuying, Wang Chunhua. Effective Integration of E-commerce and ERP System -- Case Study of Oil Company[J] Chinese High-tech Enterprises, 2010, (07).

[8] Qi Shanshan International Electronic Commerce Road of Manufacturing Companies in the 
Context of Globalization [J]. Commodity and Quality, 2011, (S6).

[9] Chen Chunlei, Li Chuanhui, Chen Feibao. Integration of ERP and E-commerce and Strategies studies. [J]. Northern Economy and Trade, 2010, (7). 